\title{
Polymorphism Rs10455872 at The Lipoprotein(A) Gene Locus Enhances the Risk of Aortic Valve Disease
}

\author{
V Tomova ${ }^{1 *}$, M Alexandrova ${ }^{2}$, M Atanasova ${ }^{3}$, T Rashev ${ }^{4}$ and M Tzekova ${ }^{5}$ \\ ${ }^{1}$ Department of Internal Diseases, St. Marina University Hospital Medical University, Bulgaria \\ ${ }^{2}$ Division of Physics and Biophysics, Medical University, Bulgaria \\ ${ }^{3}$ Division of Biology, Medical University, Bulgaria \\ ${ }^{4}$ University Scientific Research Laboratory, Medical University, Bulgaria \\ ${ }^{5}$ Second Clinic of Cardiology, University Hospital, Medical University, Bulgaria
}

Submission: January 22, 2018; Published: February 23, 2018

*Corresponding author: Vesela Tomova, Head of the Department of Internal Diseases, University Hospital "St. Marina", Medical University, Pleven, Bulgaria, Email: vessela.dimova@gmail.com

\section{Summary}

Introduction: Calcific aortic valve disease (CAVD) is a disorder of high social significance not only because it is widespread but also because it can progress subclinically over an extended period. After the development of severe aortic stenosis, the 2-year survival rate in the absence of surgical intervention is about $50 \%$. Currently, the causes of this pathological condition and its exacerbation mechanisms remain unknown.

Aim: To establish whether polymorphism rs10455872 at the lipoprotein (a) (LP(a)) gene locus, encoding LP(a), increases the risk of aortic valve disease.

Material and methods: A total of 146 individuals (38 controls and 108 patients with CAVD) were examined. The blood biochemical parameters on admission were measured using standard techniques. Electrocardiography and transthoracic echocardiography were performed on all the subjects included in the study. Genotyping for LPA rs10455872 polymorphisms ( $>$ >G, intron 25) was performed using real-time PCR and specific software.

Results: Obesity degree and serum level of LDL-cholesterol were higher in patients than in controls. We established that $19.4 \%$ of patients and $5.3 \%$ of controls had at least one mutant allele. A significant association was obtained between rs 10455872 polymorphism and the cardiovascular disease $(\chi 2=4.259, \mathrm{p}=0.039)$. This association strength was found by the odds ratio, $0 \mathrm{R}=4.345$ (95\% CI 0.968-19.501).

Conclusion: Individuals with at least one mutant allele are four times more likely to develop CAVD as compared to persons of normal genotype. Confirming the genetic nature of the disease can help prevent or optimize treatment of this frequently encountered socially significant disease.

Keywords: Aortic stenosis; Calcific aortic valve disease; Lipoprotein(a); rs10455872

Abbreviations: CAVD: Calcific Aortic Valve Disease; HDL: Cholesterol-High-Density Cholesterol; LDL: Cholesterol -Low-Density Cholesterol; Lp(a): Lipoprotein(a); LPA: Locus -Gene Locus Coding for Lipoprotein(a); OR: Odds Ratio; PCR: Polymerase Chain Reaction; rs10455872: reference SNP 10455872; SNP: Single Nucleotide Polymorphism

\section{Introduction}

Calcific aortic valve disease (CAVD) is the third most common cardiovascular disease in adults, after arterial hypertension and ischemic heart disease. It affects between 2 and $7 \%$ of people over 65 years of age [1], with incidence of about $12 \%$ in subjects older than 75 years of age [2]. Clinically manifested high gradient aortic stenosis is the most common heart defect requiring surgical treatment and the second most common cause leading to heart surgery in the European Union and the USA (after coronary artery bypass).

There is a long "silent" subclinical period of 7-8 to 10 years between the first pathological changes in the aortic valve and the development of high gradient aortic stenosis. After the onset of initial clinical symptoms (angina pectoris, congestive heart failure, syncope, rhythm and conduction disorders), the two-year survival rate of patients who do not have prosthetic aortic valve 
replacement is about 50\% [3]. The risk of ischemic heart disease or myocardial infarction in patients with CAVD (even of those with no severe symptoms) is significantly higher in comparison with subjects of the same age but not suffering from CAVD [4-7].

Currently, the causes of this pathological condition and its exacerbation mechanisms, resulting in calcified aortic valve deformity, sclerosis, and aortic valve dysfunction, remain unknown. Recently, particular attention has been paid to the pathological role of genetic factors [2,8-13] and lipoprotein(a), the latter having a significant contribution to the development of CAVD. Data on genetic biomarkers that are predictive of the occurrence and progression of valve calcification, however, is still insufficient.

Large-scale meta-analyses in multiethnic populationbased studies (Framingham Heart Study, the Age, Gene/ Environment Susceptibility-Reykjavik Study, Multi-Ethnic Study of Atherosclerosis, Heinz Nixdorf Recall Study, Malmö Diet and Cancer Study (MDCS), and the Copenhagen City Heart Study) have found that a single nucleotide polymorphism (SPN) at LPAlocus (rs10455872) is significantly associated with aortic valve calcification [2]. The mechanisms responsible for this relationship and the way in which the genetic polymorphisms affect CAVD initiation and progression have not been entirely clarified. Data on the link of LPA rs10455872 polymorphism to the calcific aortic valve disease have not been published in Bulgaria so far.

The study aimed to establish whether the polymorphism rs10455872 at the lipoprotein(a) (LPA gene locus, encoding $\mathrm{Lp}(\mathrm{a})$, increases the risk of aortic valve disease.

\section{Material and Methods}

\section{Study population}

Initially, the study included 156 patients, treated at Cardiology Clinic II, University Hospital -Pleven between May 2015 and April 2016. Ten subjects ( 6 of the oldest in the target group and 4 of the youngest in the control group) were excluded from the analysis because of the significant age difference established between the investigated groups. Of the remainder (146 patients), 38 were controls (patients with structurally and functionally normal aortic valve), and 108 were patients with echocardiographic evidence of CAVD. This latter group included patients with all forms of the disease, including subclinical ones: aortic valve calcification (confirmed by CT scan), aortic sclerosis (echocardiographically confirmed thickening and calcification), as well as clinically manifested aortic stenosis.

Criteria for including the controls in the study were as follows: age over 50 years and lack of echocardiographic data for structural aortic valve disease. Criteria for inclusion of patients in the target group were age over 50 years, systolic aortic murmur and morphological changes presenting with calcification and aortic valve sclerosis (with or without hemodynamically significant stenosis), assessed by echocardiographic methods. The study excluded individuals with aortic valve dysfunction due to congenital conjoined commissures or hypoplastic valve, rheumatic endocarditis, infectious endocarditis with vegetation causing obstruction to blood flow through valve, primary and secondary calcium metabolism disorders with an increased tendency to calcium deposition in tissues of patients with advanced renal insufficiency, primary and secondary hyperparathyroidism). All participants in the study were aware of its goals and methods and gave written informed consent for genetic testing.

\section{Biochemical blood analysis}

Peripheral venous blood was collected in a fasting state in EDTA-containing vacutainers $(10 \mathrm{~mL}, \mathrm{VWR}$, Austria) for further DNA isolation and analysis. Glucose, total cholesterol, LDLcholesterol, HDL-cholesterol, triglycerides, and creatinine levels were determined by standard methods.

\section{Electro-and echocardiography}

Detailed histories were taken, and physical examinations were performed on both controls and CAVD patients. At the time of inclusion in the study, all patients underwent electrocardiographic examination (12 leads, $25 \mathrm{~mm} / \mathrm{s}$ recording speed and $10 \mathrm{~mm} / \mathrm{mV}$ sensitivity). Cardiac rhythm, presence or absence of conduction and rhythm disorders, the presence of left ventricular hypertrophy and ischemia/survived myocardial infarction were assessed.

A transthoracic echocardiography was performed on the study population, using a standard echocardiographic procedure (Phillips HD 7и Esaote My Lab 7), according to the standards of European Echocardiography Association, by two-dimensional (B-mode), one-dimensional (M-mode) and conventional Doppler echocardiography (CW-Doppler, PW-Doppler, Colour-Doppler). Heart dimensions and volumes, valve status, aortic root, ascending aorta and pericardium were evaluated. Calcification of the aortic valve was quantified, and in each case presence of calcium deposits on valvular structures with thickening and deformation of the cusps was considered pathological.

\section{DNA-analysis and genetic variants}

Genetic research was carried out at the University Research Laboratory of Medical University -Pleven. Isolation of DNA from venous blood was performed by saline extraction with AccuPrep Genomic DNA Extraction Kit -BIONEER according to approved laboratory protocols and manufacturer's recommendations. Genotyping of the $A>G$ polymorphism was performed (rs10455872) in intron 25 of the gene, coding Lp(a) with TaqMan Pre-designed SNP Genotyping Assay (Life Technologies), at platform PicoReal 96 -Real-time PCR and subsequent analysis of allelic profiles with specialized software (Thermoscientific).

\section{Statistical analysis}

The software program SPSS version 19.0 (SPSS, Chicago, IL, USA) was used for data analysis. The chi-squared test was applied to compare proportions between the patient groups. The interval variables were represented as mean ( \pm standard deviation, SD) or median $\left(25^{\text {th }}-75^{\text {th }}\right.$ percentiles $)$ depending on the type of distribution. Normality of data was checked with the 
Shapiro-Wilk test. The significance of differences between groups was assessed by Student's t-test and one-way analysis of variance for normally distributed data, and by the Mann-Whitney U-test and Kruskal-Wallis test for non-parametric data. The existence of an association between the genotype of the patients studied, and CAVD was sought using the Pearson $\chi 2$-test, and the risk evaluation was performed using cross tabulation. A value of $p$ $<0.05$ was considered statistically significant. The study was approved by the Ethics Commission at the Medical University Pleven.

\section{Results}

\section{Baseline characteristics of the study population}

Table 1: Baseline characteristics of the study population.

\begin{tabular}{|c|c|c|c|}
\hline Parameter & Controls & Patients with CAVD & $\mathbf{p}$ \\
\hline Gendermen, $\mathrm{n}(\%)$ women, $\mathrm{n}(\%)$ & $\begin{array}{l}17(45) \\
21(55)\end{array}$ & $\begin{array}{l}51(47) \\
57(53)\end{array}$ & 0.792 \\
\hline $\begin{array}{l}\text { Age [years], median }(25-75 \\
\text { percentile })\end{array}$ & $70(63-74)$ & $72(67-76)$ & 0.055 \\
\hline Smoking, n (\%) & $18(47)$ & $36(33)$ & 0.123 \\
\hline Arterial hypertension, n (\%) & $35(92)$ & $95(88)$ & 0.482 \\
\hline Diabetes mellitus, n (\%) & $17(45)$ & $40(37)$ & 0.403 \\
\hline Obesity, n (\%) & $24(63)$ & $43(40)$ & $0.013^{*}$ \\
\hline Ischemic heart disease, $\mathrm{n}(\%)$ & $22(58)$ & $56(52)$ & 0.521 \\
\hline Ascending aortic dilatation, n (\%) & $7(18)$ & $38(35)$ & 0.054 \\
\hline $\begin{array}{c}\text { Early chronic renal insufficiency, } \\
\text { n (\%) }\end{array}$ & $5(13)$ & $13(12)$ & 1 \\
\hline $\begin{array}{l}\text { Serum glucose }[\mathrm{mmol} / \mathrm{L}] \text {, median } \\
(25-75 \text { percentile })\end{array}$ & $6.0(5.1-7.4)$ & $5.8(5.1-6.8)$ & 0.625 \\
\hline $\begin{array}{l}\text { Totalcholesterol }[\mathrm{mmol} / \mathrm{L}] \text {, median } \\
\text { (25-75 percentile) }\end{array}$ & $4.31(3.69-5.09)$ & $4.85(3.99-5.77)$ & 0.063 \\
\hline $\begin{array}{l}\text { HDL-cholesterol }[\mathrm{mmol} / \mathrm{L}] \\
\text { median }(25-5 \text { percentile })\end{array}$ & $1.23(1.00-1.57)$ & $1.30(1.10-1.56)$ & 0.756 \\
\hline $\begin{array}{l}\text { LDL-cholesterol }[\mathrm{mmol} / \mathrm{L}] \text {, median } \\
\quad(25-75 \text { percentile })\end{array}$ & $2.22(1.97-3.20)$ & $2.82(2.09-3.57)$ & $0.022^{*}$ \\
\hline $\begin{array}{l}\text { Triglycerides }[\mathrm{mmol} / \mathrm{L}], \text { median } \\
\quad(25-75 \text { percentile })\end{array}$ & $1.39(0.98-1.95)$ & $1.23(0.82-1.78)$ & 0.302 \\
\hline
\end{tabular}

The demographic characteristics and some common cardiovascular risk factors of the study population are shown in Table 1. Sixty-eight (47\%) of the 146 patients included in the study were males. The age of the control group varied between 56 and 79 years (median 70) and that of patients with CAVD - between 53 and 83 years (median 72). No statistically significant differences existed between the target group and controls regarding gender.

Obesity degree (Table 1) and serum level of LDL-cholesterol (Figure 1) were significantly higher in patients with CAVD than in the controls. 


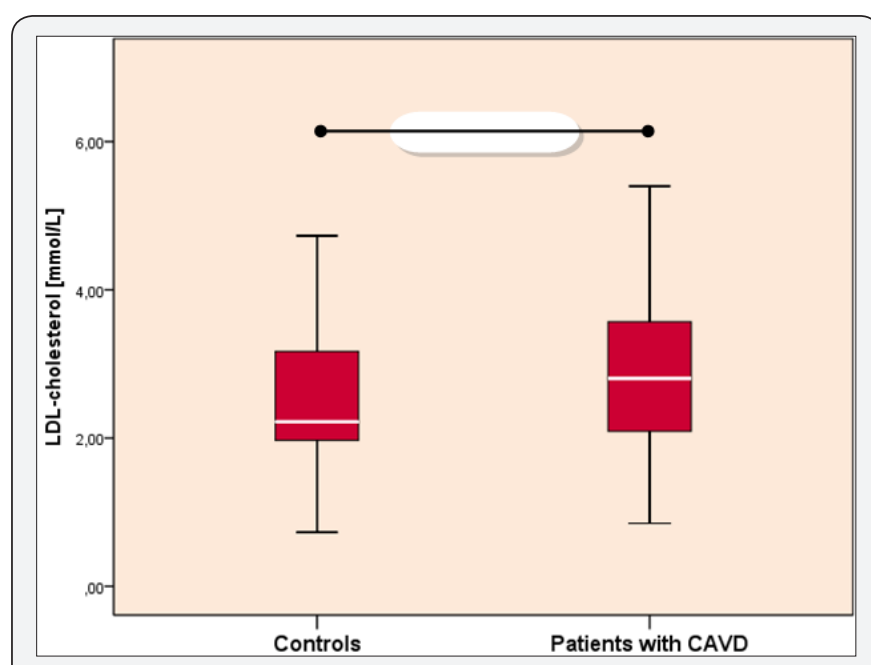

Figure 1: LDL-cholesterol levels in patients with calcific aortic valve disease and control subjects.

The role of LPA rs10455872 polymorphisms $(A>G$, intron 25) in the incidence of aortic valve disease

We studied the role of rs10455872 polymorphisms in the incidence of aortic valve disease using descriptive statistics. It was established that $19.4 \%$ of the patients with CAVD and $5.3 \%$ of the controls had at least one mutant allele (Table 2). A significant association was obtained between rs10455872 polymorphism and the cardiovascular disease $(\chi 2=4.259, \mathrm{p}=0.039)$.

Table 2: Cross tabulation table of genotype/study population.

\begin{tabular}{|c|c|c|c|c|}
\hline & & \multicolumn{2}{|c|}{ CAVD } & \multirow{2}{*}{ Total } \\
\hline & & Yes & No & \\
\hline \multirow{2}{*}{$\begin{array}{c}\text { Genotype } \\
\text { Mutant }\end{array}$} & \multirow{2}{*}{$\begin{array}{c}\text { Count\% } \\
\text { within } \\
\text { genotype }\end{array}$} & 21 & 2 & 23 \\
\hline & & $19.40 \%$ & $5.30 \%$ & $15.80 \%$ \\
\hline \multirow{2}{*}{ Normal } & \multirow{2}{*}{$\begin{array}{c}\text { Count\% } \\
\text { within } \\
\text { genotype }\end{array}$} & 87 & 36 & 123 \\
\hline & & $80.60 \%$ & $94.70 \%$ & $84.20 \%$ \\
\hline \multirow{2}{*}{ Total } & \multirow{2}{*}{$\begin{array}{l}\text { Count\% } \\
\text { within } \\
\text { genotype }\end{array}$} & 108 & 38 & 146 \\
\hline & & $100.00 \%$ & $100.00 \%$ & $100.00 \%$ \\
\hline
\end{tabular}

Table 3: Risk estimate for CAVD.

\begin{tabular}{|c|c|c|c|}
\hline \multirow{2}{*}{} & \multirow{2}{*}{ Value } & \multicolumn{2}{|c|}{$\begin{array}{c}\text { 95\% Confidence } \\
\text { Interval }\end{array}$} \\
\cline { 3 - 4 } & & Lower & Upper \\
\hline $\begin{array}{c}\text { Odds ratio for having mutant versus } \\
\text { normal genotype }\end{array}$ & 4.345 & 0.968 & 19.501 \\
\hline For cohort CAVD=yes & 1.291 & 1.089 & 1.53 \\
\hline For cohort CAVD=no & 0.297 & 0.077 & 1.149 \\
\hline N of valid cases & 146 & & \\
\hline
\end{tabular}

The association strength was obtained by the Odds ratio (Table 3 ), which in this case was equal to the ratio of the odds of having CAVD in the presence of at least one mutant allele to the odds of having CAVD in case of a normal genotype (OR=4.345 (95\% CI $0.968-19.501)$ ). This result shows that CAVD is four times more likely to occur in individuals having at least one mutant allele as compared to those with a normal genotype.

\section{Discussion}

The most common morphological variant of aortic stenosis in patients over 50 years of age is calcific aortic stenosis. The condition has long been attributed to gradual age-related "wearing out" of the valve. Recently, it has been shown that genetic variation in LPA-locus causes calcific aortic valve disease [2,8,9,11-13]. Currently, it is also thought that the pathological process of aortic calcification is accompanied by chronic inflammation, involving genetic, biochemical and humoral factors $[4,14]$. So far, genetic investigations have not shed enough light on the prognostic and predictive potential of genetic markers of valve calcification.

In this study, CAVD was found to be four times more likely to occur in individuals having at least one mutant allele as compared to individuals with a normal genotype. Such a result has been confirmed by other authors, who reported that SNP rs10455872 in the Lp (a) gene was strongly associated with aortic valve calcification $[2,12]$.

Furthermore, we established that serum levels of LDL cholesterol in CAVD patients were significantly higher than those in controls. It is known that oxidized lipoproteins, and Lp(a) in particular, are involved in atherogenesis. They are highly cytotoxic and stimulate inflammatory activity and mineralization $[10,15,16]$.

It should be noted that processes of calcification and atherosclerosis are similar. However, the cellular and mineral components of these two lesions are significantly different. These differences explain to a certain extent why only about $40 \%$ of patients with severe degenerative aortic stenosis have significant coronary artery disease but most of those with significant coronary stenosis do not have stenosis of the aortic valves $[4,17]$. Another important piece of clinical evidence, demonstrating the difference between calcification and atherosclerosis, is the effect of lipid-lowering statin therapy. This therapy has been shown to favorably affect the course of the atherosclerotic process in the vessels but has no effect on the progression of CAVD $[18,19]$.

Our data, togehter with results published by other authors, suggest that the synergistic effect of genetic factors that determine individual variations in the structure of Lp (a) on one hand, and the inflammatory processes, on the other hand, leads to the formation and exacerbation of valvular lesions in CAVD.

Further studies are needed to better explain the relationship between genetic variations in $\mathrm{Lp}(\mathrm{a})$ levels and the progression of calcific aortic valve disease. Such studies could reveal chances to lower Lp(a) levels through medication in the early phase of CAVD that might help delay or stop the progression of the disease.

\section{Acknowledgement}

The study was financially supported by Medical University Pleven (Project No 6/2015). 


\section{References}

1. Vahanian A, Alfieri O, Andreotti F, Antunes MJ, Barón-Esquivias G, et al. (2012) Guidelines on the management of valvular heart disease (version 2012). Eur Heart J 33(19): 2451-2496.

2. Thanassoulis G (2016) Lipoprotein (a) in calcific aortic valve disease: from genomics to novel drug target for aortic stenosis. J Lipid Res 57(6): 917-924.

3. Rosenhek R, Binder T, Porenta G, Lang I, Christ G, et al. (2000) Predictors of outcome in severe, asymptomaticaortic stenosis. N Engl J Med 343(9): 611-617.

4. Koleva K, Zlatareva N, Gudev A (2007) A new approach to degenerative aortic stenosis. Cardiovascular diseases 38(4): 14-19.

5. Carabello BA, Paulus WJ (2009) Aortic stenosis. Lancet 373(9667): 956-966.

6. Cosmi JE, Kort S, Tunick PA, Rosenzweig BP, Freedberg RS, et al. (2002) The risk of the development of aortic stenosis in patients with "benign" aortic valve thickening. Arch Intern Med 162(20): 2345-2347.

7. Otto CM, Lind BK, Kitzman DW, Gersh BJ, Siscovick DS (1999) Association of aortic-valvesclerosis with cardiovascular mortality and morbidity in the elderly. N Engl J Med 341(3): 142-147.

8. Gaudreault N, Ducharme V, Lamontagne M, Guauque-Olarte S, Mathieu $\mathrm{P}$, et al. (2011) Replication of genetic association studies in aortic stenosis in adults. Am J Cardiol 108(9): 1305-1310.

9. Kutikhin AG, Yuzhalin AE, Brusina EB, Ponasenko AV, Golovkin AS, et al. (2014) Genetic predisposition to calcific aortic stenosis and mitral annular calcification. Mol Biol Rep 41(9): 5645-5663.

10. Nordestgaard BG, Chapman MJ, RayK, Borén J, Andreotti F, et al. (2010) Lipoprotein(a) as a cardiovascular risk factor: current status. Eur Heart J 31(23): 2844-2853.
11. Ortlepp JR, Schmitz F, Mevissen V, Weiss S, Huster J, et al. (2004) The amount of calcium-deficient hexagonal hydroxyapatite in aortic valves is influenced by gender and associated with genetic polymorphisms in patients with severe calcific aortic stenosis. Eur Heart J 25(6): 514522.

12. Thanassoulis G, Campbell CY, Owens DS, Smith JG, Smith AV, et al. (2013) Genetic associations with valvular calcification and aortic stenosis. N Engl J Med 368(6): 503-512.

13. Thanassoulis G, Massaro JM, Cury R, Manders E, Benjamin EJ, et al. (2010) Associations of long-term and early adult atherosclerosis risk factors with aortic and mitral valve calcium. J Am Coll Cardiol 55(22): 2491-2498.

14. Hughes BR, Chhoud G, Mehta JL (2005) Aortic stenosis: is it simply a degenerative process or an active atherosclerotic process? Clin Cardiol 28(3): 111-114.

15. Bozbas H, Yildirir A, Atar I, Pirat B, Eroglu S, et al. (2007) Effects of serum levels of novel atherosclerotic risk factors on aortic valve calcification. J Heart Valve Dis 16(4): 387-393.

16. Clarke R, Peden JF, Hopewell JC, Kyriakou T, Goel A, et al. (2009) Genetic variants associated with $\mathrm{Lp}(\mathrm{a})$ lipoprotein level and coronary disease. N Engl J Med 361(26): 2518-2528.

17. Kamenova Z, Grigorov MI, Ingeliev M, Petrova G, Pesheva B, et al. (2012) Correlation between severity of degenerative aortic stenosis and coronary disease. MedInfo 4(9): 22-26.

18. Parolari A, Loardi C, Mussoni L, Cavallotti L, Camera M, et al. (2009) Nonrheumatic calcific aortic stenosis: an overview from basic science to pharmacological prevention. Eur J Cardiothorac Surg 35(3): 493504.

19. Trayanov I (2007) Aortic stenosis and aortic regurgitation (review). Cardio D 4(2): 34-41.

\begin{tabular}{l} 
Your next submission with Juniper Publishers \\
will reach you the below assets \\
- Quality Editorial service \\
- Swift Peer Review \\
- Reprints availability \\
- E-prints Service \\
- Manuscript Podcast for convenient understanding \\
- Global attainment for your research \\
- Manuscript accessibility in different formats \\
( Pdf, E-pub, Full Text, Audio) \\
- Unceasing customer service \\
Track the below URL for one-step submission \\
https://juniperpublishers.com/online-submission.php \\
\hline
\end{tabular}

